Western University

Scholarship@Western

Aboriginal Policy Research Consortium International (APRCi)

2012

\title{
Building Relationships with Aboriginal People: A Cultural Mapping Toolbox
}

(Brian) Jim Stewart

Julaine Allan

Follow this and additional works at: https://ir.lib.uwo.ca/aprci

Part of the Social Work Commons

Citation of this paper:

Stewart, (Brian) Jim and Allan, Julaine, "Building Relationships with Aboriginal People: A Cultural Mapping Toolbox" (2012).

Aboriginal Policy Research Consortium International (APRCi). 176.

https://ir.lib.uwo.ca/aprci/176 
This article was downloaded by: [University of Western Ontario]

On: 21 December 2012, At: 11:42

Publisher: Routledge

Informa Ltd Registered in England and Wales Registered Number: 1072954 Registered

office: Mortimer House, 37-41 Mortimer Street, London W1T 3J H, UK

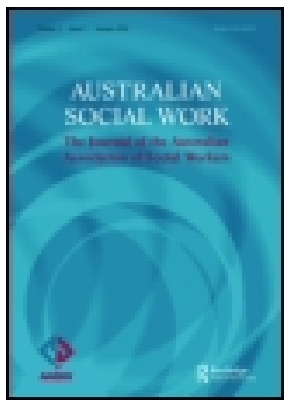

\section{Australian Social Work}

Publication details, including instructions for authors and subscription information:

http:// www.tandfonline.com/loi/ rasw20

\section{Building Relationships with Aboriginal People: A Cultural Mapping Toolbox}

(Brian) Jim Stewart ${ }^{a} \&$ J ulaine Allan ${ }^{b}$

a Western Local Health Network - Mental Health and Drug and Alcohol Office (MHDAO), Dubbo, New South Wales, Australia

${ }^{b}$ The Lyndon Community, Kite St, Orange, New South Wales, Australia

Version of record first published: 13 Nov 2012.

To cite this article: (Brian) J im Stewart \& J ulaine Allan (2012): Building Relationships with Aboriginal People: A Cultural Mapping Toolbox, Australian Social Work, DOI: 10. 1080/ 0312407X. 2012. 708937

To link to this article: http:// dx.doi.org/ 10.1080/ 0312407X. 2012.708937

\section{PLEASE SCROLL DOWN FOR ARTICLE}

Full terms and conditions of use: http://www.tandfonline.com/page/terms-andconditions

This article may be used for research, teaching, and private study purposes. Any substantial or systematic reproduction, redistribution, reselling, loan, sub-licensing, systematic supply, or distribution in any form to anyone is expressly forbidden.

The publisher does not give any warranty express or implied or make any representation that the contents will be complete or accurate or up to date. The accuracy of any instructions, formulae, and drug doses should be independently verified with primary sources. The publisher shall not be liable for any loss, actions, claims, proceedings, demand, or costs or damages whatsoever or howsoever caused arising directly or indirectly in connection with or arising out of the use of this material. 


\title{
PRACTICE, POLICY, \& PERSPECTIVES
}

\section{Building Relationships with Aboriginal People: A Cultural Mapping Toolbox}

\author{
(Brian) Jim Stewart ${ }^{a}$ \& Julaine Allan ${ }^{\mathrm{b}, *}$ \\ ${ }^{a}$ Western Local Health Network - Mental Health and Drug and Alcohol Office (MHDAO), Dubbo,

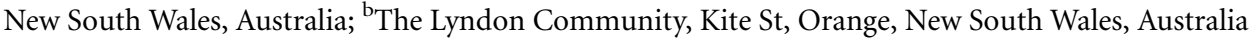

\begin{abstract}
This article describes a cultural mapping tool developed specifically for working with Aboriginal people experiencing mental health problems. The tool has broad scope, drawing from ecological and systems approaches. It will assist social workers to understand cultural and family obligations and build relationships with Aboriginal service users. Students learning about cultural diversity have expressed concern about asking culturally-sensitive questions. Australian human service workers typically state they feel inadequate in addressing Aboriginal culture in their practice approaches. The three components of the cultural mapping toolbox, (a) the social and emotional wellbeing cluster map, (b) the community and cultural diversity map, and (c) the migration map, provide social workers with a way of supporting a culturally connected lifestyle in contemporary society.
\end{abstract}

Keywords: Indigenous Knowledge; Culturally Sensitive Social Work; Social Work Practice

Aboriginal and Torres Strait Islander people are overrepresented in Australia's institutions of surveillance and control-jails and child protection agencies chief among them (Australian Bureau of Statistics [ABS] \& Australian Institute of Health and Welfare [AIHW], 2008; AIHW 2006). The damage perpetrated by policies resulting in the Stolen Generations - the forced removal of children from Aboriginal and Torres Strait Islander Families for over 100 years, between 1869 and the 1970s (Human Rights and Equal Opportunities Commission [HREOC], 1997; Read, 1981) and other overt and covert acts of racism is demonstrated in a swathe of statistics such as decreased life expectancy, low income levels, and low educational attainment for Aboriginal people (AIHW, 2011). Strategies to redress the impact of Australia's white colonisation are being implemented. Indigenous concepts of health are reflected in social and emotional wellbeing frameworks, concepts of cultural competence, and national "closing the gap" initiatives (e.g., Department of Families, Housing, Community Services and Indigenous Affairs [FaHCSIA], 2011). However,

\footnotetext{
${ }^{*}$ Correspondence to: Dr Julaine Allan, Research Manager, The Lyndon Community, Research and Training Program, PO Box 9324, Orange, New South Wales 2800, Australia. E-mail: jallan@lyndoncommunity.org.au Accepted 17 June 2012
} 


\section{J. Stewart \& J. Allan}

there are few practical tools to facilitate social work interventions with Aboriginal people. This paper describes a cultural mapping tool developed specifically for working with Aboriginal people experiencing mental health problems. The tool has broad scope, drawing from ecological and systems approaches. It will assist social workers to understand cultural and family obligations and build relationships with Aboriginal service users.

The authors of this article work in mental health and drug and alcohol services in rural New South Wales (NSW). Author 1(JS) is an Aboriginal man, who has spent the past 20 years working with many Aboriginal communities throughout north and western NSW. Author 2 (JA) is a nonIndigenous social work researcher working with Aboriginal communities on drug and alcohol service delivery. JS developed the cultural mapping tool to provide a way for nonAboriginal workers to gather the information they needed about their service user's context, including factors influencing wellbeing such as supportive and unsupportive relationships, health and wellbeing, and practical needs such as housing and income.

There are three components in the cultural mapping toolbox: a social and emotional wellbeing cluster map, a community and cultural diversity map, and a migration map. This paper provides examples of the way the tools can be used. The term Aboriginal is used to refer to Australian Indigenous people rather than Aboriginal and Torres Strait Islander people. Aboriginal people were the first inhabitants of the area now known as NSW. Aboriginal is considered the most appropriate term to use in relation to NSW communities (NSW Health, 2004). The suggested mapping practices, particularly the migration map, also need to be understood within the NSW context, where Aboriginal communities are fractured by dispossession and forced migration onto missions (HREOC, 1997).

Culture and ethnicity are intrinsic determinants of health and wellbeing and critical to helping relationships. Cultural mapping has the potential to improve social workers' cultural competence (Dunn \& Levitt, 2000). Students learning about cultural diversity have expressed concern about asking culturally sensitive questions (Shellenberger et al., 2007). Australian human service workers typically state they feel inadequate in addressing Aboriginal culture in their practice approaches (Roche, Pidd \& Duraisingam, 2009). Cultural awareness or cultural competence training for staff is the usual solution to making agencies deliver appropriate services for Aboriginal clients. Typically, cultural awareness training consists of information and stories about white settlement of Australia, dispossession of Aboriginal land, and racist policies and practices (Secretariat of National Aboriginal and Islander Child Care [SNAICC], 2008). There is a hope that information will lead to behaviour or attitudinal change among nonAboriginal workers.

Cultural competence has been defined as "a set of congruent behaviours, attitudes, and policies that come together in a system, agency, or among professionals that enable them to work effectively in cross-cultural settings" (Char Tong \& Cross, 1991, as cited in Victorian Aboriginal Child Care Agency, 2008). However, there are no reports of specific practice change proposed or evaluated following cultural 
competency training about Australian Aboriginal people, even though workplace practices and workers are expected to change. Instead, explanations of desired cultural competency tend to be circular and nonspecific. For example:

For services working with Aboriginal and Torres Strait Islander communities, being culturally competent means working within a framework that recognises and respects the central importance of culture and identity to Aboriginal and Torres Strait Islander people and communities, and working in ways that safeguard the importance of culture, and supports their capacity to strengthen the place of culture and identity in promoting social and emotional well-being. This means providing programs and services that are culturally appropriate. (SNAICC, 2008, p. 99)

This explanation describes cultural competence as providing culturally appropriate services and working effectively but does not define what a culturally appropriate service is or what a framework that values culture could look like. However, there is an expectation that all mainstream services are culturally inappropriate and cannot achieve good outcomes for Aboriginal people (Hayman, White, \& Spurling, 2009). Literature designed to assist in developing culturally-appropriate approaches (e.g., Australian Drug Foundation [ADF], 2004; SNAICC, 2008), promotes values and attitudes necessary to reduce racism but does not provide practice guides or strategies. The cultural mapping toolbox provides a practical way to be culturally competent by highlighting the importance of family and community relationships and the ways they operate.

\section{Kinship and Family Relationships in Aboriginal Communities}

A collectivist or allocentric worldview is found in a number of Indigenous cultures around the world. It is manifested in a shared sense of responsibility to care for children, provide financial and emotional support, and participate in decisionmaking efforts that involve one or more members of the family (Rigazio-DiGilio, Ivey, Kunkler-Peck, \& Grady, 2005). This is substantially different from a traditional individualised western worldview and concept of family and community responsibilities. However, Aboriginal Australians do not depend on biological bonds to identify family members. Traditional Aboriginal societies were organised by their language group, which were then broken down into smaller "local groups", for instance, clans, mobs, or "families" (Zubrick et al., 2005). Hence, individuals usually identified a relationship with all other individuals who spoke the same language, not relying on genetic bonds alone to classify kinship ties (Elston \& Dade Smith, 2007; Zubrick et al., 2005). For Aboriginal people, this concept of kinship allows members to invariably refer to their extended family by their relationship names rather than a personal name, roles that intrinsically infer social obligations and interactional behaviour and are synonymous with country, spirituality, and ritual (Green \& Baldry, 2008; Orford et al., 2005). In the contemporary context, extended kinship relationships continue to be an identifiable Aboriginal trait, regardless of the preservation of 
traditional culture or not. Extended kinship relationships exist even among the third of Aboriginal families in two-parent households (Zubrick et al., 2005). This is significant for the construction of Aboriginal identity, acceptance, and community inclusion.

\section{Genograms and Ecomapping}

Genograms have been used by social workers and counsellors as assessment tools since the 1950s. Genograms depict biological and family relationships in a structured way, typically over three generations (Butler, 2008). Genograms have proved useful for the evaluation of family systems, including births, deaths, physical problems, emotional and mental symptoms, relationship conflicts, and educational achievement (Guerin \& Pendagast, 1976). The diagram was intended to reduce lengthy written notes but also to represent family processes and functioning in a way that had meaning in relation to current problems experienced by the service user (Butler, 2008). Traditional genograms have a biological base but incorporate strong links to psychoanalytic interpretations of behaviour. For example:

A horizontal jagged line between individuals reflects conflict, while a line with a small arrow on the end from parent(s) into the focused on child notes projection. Emotional cutoff is shown by a downward half-circle placed underneath the identified patient and his or her parents. (Kerr \& Bowen, 1988, p. 307, cited in Butler, 2008, p. 172)

The nuclear family and its functioning is most often the system of interest in a genogram. Symptoms of problems represented in a genogram reflect a family's functioning within a specific culture and community, as well as within family roles and stages (McGoldrick, Gerson, \& Petry, 2008). However, the process of creating a genogram has been identified as being as significant as the drawing itself. Service users reflect on relationships, connections, and the systems surrounding them, as the picture is created (McGoldrick et al., 2008; Skowron, Holmes, \& Sabatelli, 2003). Further work has highlighted the importance of sociopolitical factors and other contextual issues in defining and working on personal problems (Kosutic et al., 2009).

Ecomaps are a variation of genograms. Ecomaps are primarily concerned with social relationships and networks and the positive or negative nature of connections or bonds (Rempel, Neufeld, \& Kushner, 2007). Ecomaps are visual representations of social relationships, typically including family, but also friends and community networks (Rempel et al. 2007). The importance of social support to assist health maintenance and wellbeing has been well documented (e.g., Nausheen, Gidron, Peveler, \& Moss-Morris, 2009). Ecomaps have been identified as a practical and accessible way to identify both positive support and social conflicts impeding wellbeing (Ray \& Street, 2005). The aim and intent of ecomaps has particular 
relevance for the holistic approach promoted by Aboriginal social and emotional wellbeing (SEWB) frameworks.

Relational issues such as divorce, step-children, and social networks represented in genograms and ecomaps are intended to be reported in an objective way. However, the genogram's detail is controlled by the enquiries and value base of the professional. A number of authors have noted that genograms typically assume Western oriented patriarchal family organisation (Kosutic et al., 2009) excluding spiritual relationships (Limb \& Hodge, 2008), cultural practices (Shellenberger et al., 2007) and kin and extended family relationships (Hunter \& Sawyer, 2006).

Constructing a picture of family relationships and social networks has three benefits. Firstly, mapping facilitates a relational process between worker and service user, promoting in-depth conversation and collaboration (Dunn \& Levitt, 2000). The mapping process is useful for engagement and hearing the concerns and experiences of the service user (Yznaga, 2008). The map is both a transparent and a transportable record of information collection. Secondly, mapping develops the scope of potential action to address problems of isolation, illness, or limited opportunity by stimulating ideas and revealing opportunities in a diagrammatic way. Diagrams are useful techniques for people who are not used to talking therapies, have limited vocabularies, have low literacy or prefer to tell stories using practical and concrete examples (Yanicki, 2005). Rempel et al. (2007), suggested genogram and ecomap processes may be particularly useful in working with men. Further diagrams are congruent with Aboriginal information systems.

Thirdly, the map identifies service providers as well as family and social networks. Human services are provided by numerous agencies, frequently with gaps and duplications across areas (Allan, Ball, \& Alston, 2009). There is a strong perception in rural areas that human services are nonexistent. However, they are more frequently hard to reach because of operating procedures and opening hours, service and referral criteria, or staff shortages (Allan \& Campbell, 2011). The mapping process can identify which agencies, if any, are involved with a service user or family and what their service provision consists of. Mapping can pinpoint agency responsibilities and monitor service delivery.

\section{Cultural Mapping Toolbox}

The three components in the cultural mapping toolbox - a social and emotional wellbeing cluster map, a community and cultural diversity map and a migration map — can all be used with Aboriginal people requiring support and assistance in some way. However, there are some key aspects to the approach that must be incorporated for the tools to be useful. Appropriate and responsive communication strategies are the key to establishing a working relationship with Aboriginal service users. In particular, developing a narrative in an informal and relaxed way to establish trust and rapport is critical. Given Aboriginal community and individual levels of mistrust of human services workers and poor experiences of intervention, 
using a cultural consultant or mentor to vouch for a worker, introducing them around the community, can enhance the development of relationships. However, because of the involuntary or reluctant nature of some social work contacts and social work roles in Aboriginal communities, worker expectations should factor in effort and time spent in building relationships, both with cultural mentors and with service users.

Knowledge of Aboriginal kin relationships is critical to developing a cultural map. Immediate biological relationships do not mean a person lived with those kin as a child. For example, aunts or uncles may have "grown up" a child rather than parents or grandparents. The mapping process is an evolving construct to identify the roles and functions of cultural members in a wellness cluster.

\section{Social and Emotional Wellbeing [SEWB] Wellness Cluster Map}

The initial step is identifying and naming people who have regular contact or a defined role with the identified service user (SEWB network). The key criterion for inclusion is regular contact, potential positive impact on social and emotional wellbeing and those who live close by. The contact could be by telephone. The network will include family members, those people who have a supervisory or mentor kinship role; for example, those who would underpin cultural values and beliefs. The extended family network may live in other communities, have infrequent contact, but can be called upon. The map should include members of the household and other service providers.

The second step in developing the map involves identifying the nature and strength of relationships between people on the map. The aim is to identify those who promote positive social and emotional wellbeing but also to include negative or stressful relationships. Trust and rapport are critical to gathering the sensitive information required for the map and it may take several meetings to develop a comprehensive history. Cultural stories about spirits and marriages, particularly if they are "wrong way" (outside a skin group or against a promised relationship (Australian Law Reform Commission [ALRC], 1986), may be avoided at first. It is useful for the worker to ask about activities the service user and the network member engage in. The degree of cultural activity is an indicator for contextualisation of cultural values and beliefs that are incorporated into daily life.

Constructing the map involves using circles within a rectangular border to represent the members who have an ongoing and immediate relationship with the service user. Family or friends who are deceased, have limited or no contact with the service user, or live a long way away are mapped outside the rectangular border. Workers may wish to colour code their maps to represent categories of relationship within the network such as children, social network, or kin responsibilities. Strength and support of relationship are represented by different types of lines between the circles. Strong support is represented by a thick line, negative relationships by a wiggly line, mutual support by an arrow going both ways, and limited or distant relationships by dotted lines. (See Figure 1.) 


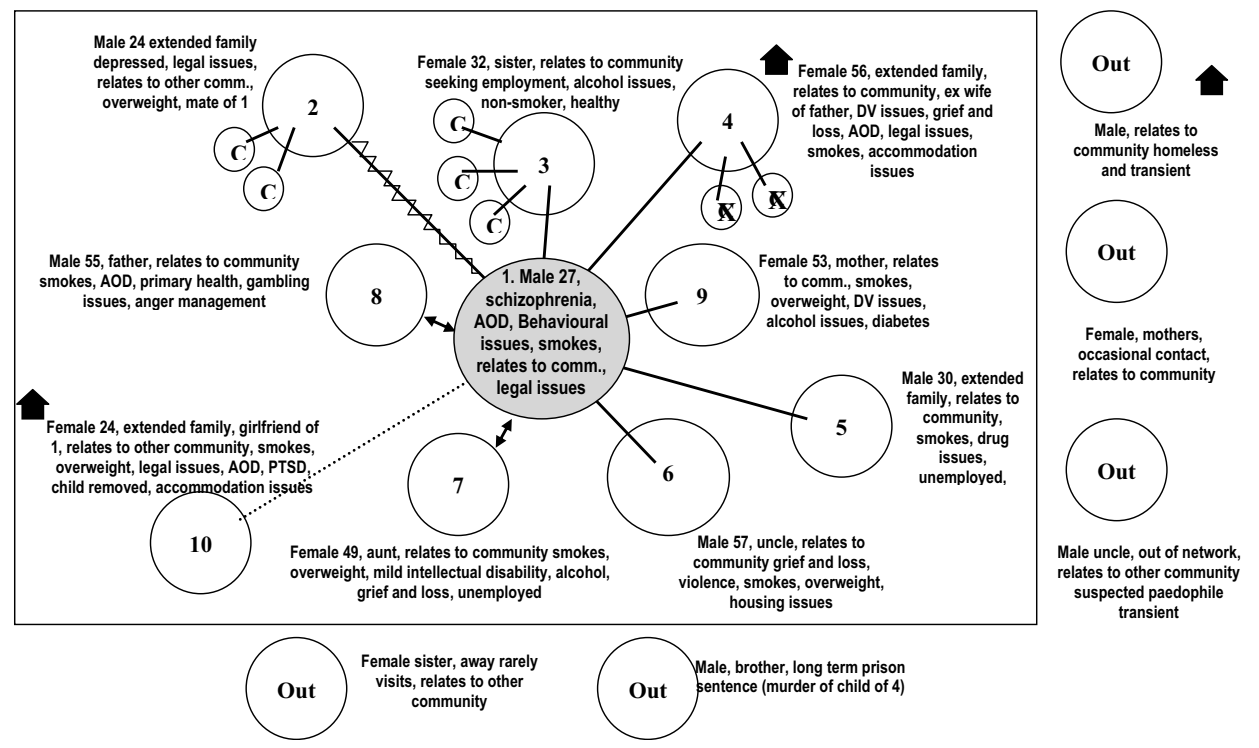

Figure 1 Aboriginal social and emotional wellbeing (SEWB) map. Jason 27 year old man with schizophrenia and alcohol and drug misuse (Number and letter key: 1 - Individual, $3,6,7,8 \& 9$ - carer and emotional support relationships, 2,4,5 \& 10 - regular ongoing social contact, Out - external person/extended family without regular contact, $\mathrm{C}-$ children). $\mathrm{AOD}=$ alcohol and other drugs; $\mathrm{PTSD}=$ post traumatic stress disorder; $\mathrm{DV}=$ domestic violence; comm = community.

\section{Cultural Diversity Kinship Links}

Family relationships significantly affect the way Aboriginal people use, or do not use, human services. Families in a community may be linked by kinship, tribal or land connections whereas other families may be recent arrivals to the area. Normal cultural diversity can result in factions or influence over access to services and resources. While the aim and intent of human services is to provide care according to need, community relationships can make an impact on which services are used and by whom. It is important to understand the community interactions where services are provided to identify the choice of service provision or facilitation being delivered.

Identify the names of large Aboriginal families and who they are related to where possible. A cultural consultant with good knowledge of the local community will be an invaluable resource for this task.

Figure 2 illustrates how to: match the kinship or country groups with those who access your program; enlist the help of other agencies to identify who access their service; and illustrate service and program coverage via a map assists service providers to address disparate community participation.

\section{Aboriginal Migration Map}

Aboriginal families frequently have regular migration pathways that support cultural connectedness to kin and ancestors. While, traditionally, Aboriginal people moved 


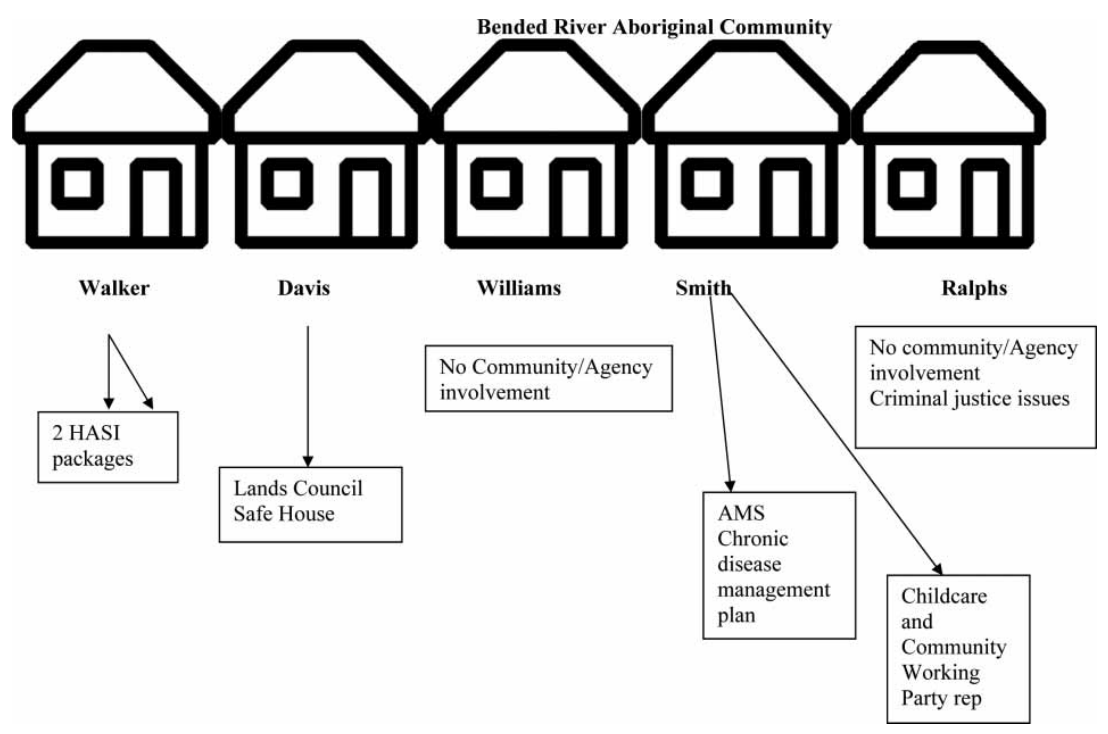

Figure 2 Bended River Aboriginal community, families, and connections (Family names are fictitious.) HASI = Housing and Accommodation Support Initiative; AMS = Aboriginal Medical Service; rep = representative.

for seasonal food, trading, and ceremonial reasons, the migration patterns have remained and have adapted. Migration pathways give rise to the number of people in premises and contribute to overcrowding but also sustain cultural networks and relationships and connections to country.

Figure 3 shows how to: identify the ancestral homelands and country of service users (Where are you from? Who is your mob/family and where are they from?); investigate migration locations (When were you last home? Where did you grow up? Have you lived anywhere else?); identify the cultural network members of other migration locations (Who are the mob you're staying with now? Where are they from?); draw the identified towns, regional centres, missions or cities, or both; and describe the relationship(s) of the locations to the service user (see Figure 3 ). The migration map assists service providers to plan for migratory lifestyles and develop support networks across locations rather than have people only identified in "lost to care" statistics.

\section{Implications for Using the Tool in Social Work Practice}

Mental health support programs have traditionally been clinically based and organised around the delivery of medical treatment to the identified patient. The result was that Aboriginal workers provided covert support and resources to families. The client or patient-centred model was unable to incorporate holistic or intersectorial service models - models that are culturally responsive to Aboriginal service users and their social and emotional well being networks. 


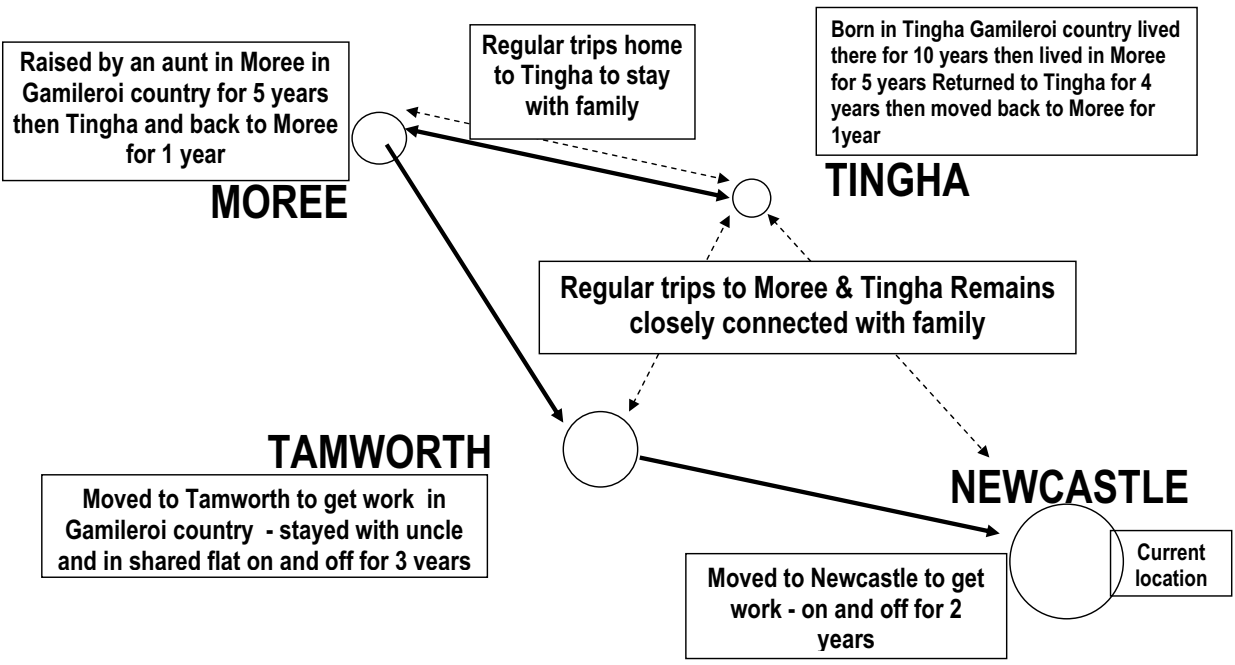

Figure 3 Aboriginal migration map.

Cultural mapping can be incorporated into care planning, case reviews, inpatient discharge schedules, and collaborative networking partnerships. Cultural mapping is inclusive of kin and community relationships, highlighting their significance. Frontline workforce, management, and executive deliberations can utilise cultural mapping to equalise disparity in Aboriginal service provision because who gets what and from whom can be identified.

NonIndigenous workers' concerns about cultural incompetence and lack of knowledge about social and emotional wellbeing are problematic for service delivery to Aboriginal people and communities. However, the mapping toolbox identifies Aboriginal cultural domains that are likely to be generic across cultural groups. Further, the mapping toolbox provides a practical means of applying cultural competence training. Cultural competence training promotes the importance of recognising cultural practices as a central organising system in Aboriginal communities (SNAICC, 2008). The mapping toolbox provides a way to make community organisation and relationships concrete.

Social work practice with Aboriginal individuals and communities can be monitored and evaluated based on the record created with the maps. Community knowledge can be documented. The maps could be used in supervision as a way of examining practice and identifying gaps in knowledge or community relationships. Further, communication between agencies and workers can be more transparent when the understanding of the Aboriginal social network is shared. However, using the cultural mapping toolbox does not remove the imperative for social workers to take time in developing relationships with Aboriginal communities. There are specific knowledge and skills related to Aboriginal kin relationships and community organisation that should be employed to avoid the pitfalls of using the mapping approach as simply a biological or technical record. In approaches to health care in 
general, holistic understandings that include social, emotional, cultural, and spiritual wellbeing as well as physical health are preferred by Aboriginal Australians. In this way, stability and strengths are built upon, in recognition that gains in any area will affect the whole person, their family, and their community (Garvey, 2008; O'Donohue, 1999). Social workers can make an important contribution to those gains by using the cultural maps.

\section{Conclusion}

Working in a crosscultural context has been described as "complex, ripped and ragged" (Auty, 2005, in Briskman, 2007, p. 90). The history of racism and punishing control over Aboriginal communities is an additional layer of complexity in the Australian context. Social workers working with Aboriginal communities need ways to negotiate the challenging terrain so well described in cultural competence training. The training will provide knowledge but not action without a means of applying it in practice. The cultural mapping toolbox offers a way forward for social work by sustaining culturally connected lifestyles in contemporary society.

\section{References}

Allan, J., Ball, P., \& Alston, M. (2009). Following the policy pathway: The impact of policy processes on children's access to healthcare in rural Australia. International Journal of Child Health and Human Development, 2, 105-113.

Allan, J., \& Campbell, M. (2011). Improving access to hard-to-reach services: A soft entry approach to drug and alcohol services for rural Australian Aboriginal communities. Social Work in Health Care, 50, 22.

Australian Bureau of Statistics [ABS] \& Australian Institute of Health and Welfare [AIHW]. (2008). The health and welfare of Australia's Aboriginal and Torres Strait Islander peoples. AIHW cat. no. IHW 21. Canberra: ABS and AIHW.

Australian Drug Foundation [ADF]. (2004). Resources for workers in the drug and alcohol field who work with Indigenous Communities. Factsheet 7. Retrieved August 18, 2010, from http://www. druginfo.adf.org.au/druginfo/fact_sheets/

Australian Institute of Health and Welfare [AIHW]. (2006). Family violence among Aboriginal and Torres Strait Islander peoples. Cat. no. IHW 17. Canberra: AIHW.

Australian Institute of Health and Welfare [AIHW]. (2011). Young Australians: Their health and wellbeing 2011. Part VII Aboriginal and Torres Strait Islander Young People. Cat. no. PHE 140. Canberra: AIHW.

Australian Law Reform Commission [ALRC]. (1986). Recognition of Aboriginal Customary Laws (ALRC Report 31)/12. Aboriginal marriages and family structures. Commonwealth of Australia. Retrieved August 18, 2011, from http://www.alrc.gov.au/publications/report-31

Briskman, L. (2007). Social work with Indigenous communities. Annandale, NSW: The Federation Press.

Butler, J. F. (2008). The family diagram and genogram: Comparisons and contrasts. The American Journal of Family Therapy, 36, 169-180.

Department of Families, Housing, Community Services and Indigenous Affairs [FaHCSIA]. (2011). Closing the gap: Prime Minister's Report 2011. Commonwealth of Australia 2011. Retrieved 
December 19, 2010, from http://www.fahcsia.gov.au/sa/indigenous/pubs/closing_the_gap/ 2011_ctg_pm_report/Documents/2011_ctg_pm_report.pdf

Dunn, A. B., \& Levitt, M. M. (2000). The genogram: From diagnostics to mutual collaboration. Family Journal: Counseling and Therapy for Couples and Families, 8, 236-244.

Elston, J., \& Dade Smith, J. (2007). Indigenous Australia. In J. Dade Smith, Australia's rural and remote health: A social justice perspective, ( $2^{\text {nd }}$ ed.) (pp. 18-47). Victoria: Tertiary Press.

Garvey, D. (2008). A review of the social and emotional wellbeing of Indigenous Australian peoples: Considerations, challenges and opportunities. Australian Indigenous Health Bulletin, 8, 1-29.

Green, S., \& Baldry, E. (2008). Building Indigenous Australian social work. Australian Social Work, $61,389-402$.

Guerin, P. J., \& Pendagast, E. (1976). Evaluation of family system and genogram. In P. Guerin (Ed.), Family therapy: Theory and practice (pp. 450-464). New York: Gardner Press.

Hayman, N. E., White, N. E., \& Spurling, G. K. (2009). Improving Indigenous patients' access to mainstream health services: The Inala experience. Medical Journal of Australia, 190, 604-606.

Human Rights and Equal Opportunity Commission [HREOC]. (1997). Bringing them home: Report of the National Inquiry into the Separation of Aboriginal and Torres Strait Islander Children from their Families. Retrieved December 19, 2011, from http://www.humanrights. gov.au/social_justice/bth_report/report/index.html

Hunter, D., \& Sawyer, C. (2006). Blending native American spirituality with individual psychology in work with children. Journal of Individual Psychology, 62, 234-250.

Kosutic, I., Garcia, M., Graves, T., Barnett, F., Hall, J., Haley, E., Rock, J., Bathon, A., \& Kaiser, B. (2009). The critical genogram: A tool for promoting critical consciousness. Journal of Feminist Family Therapy, 21, 151-176.

Limb, G., \& Hodge, D. (2008). Developing spiritual competency with Native Americans: Promoting wellness through balance and harmony. Families in Society, 89, 615-622.

McGoldrick, M., Gerson, R., \& Petry, S. (2008). Genograms: Assessment and intervention (3rd ed.). New York: Norton Professional Books.

Nausheen, B., Gidron, Y., Peveler, R., \& Moss-Morris, R. (2009). Social support and cancer progression: A systematic review. Journal of Psychosomatic Research, 67, 403-415.

New South Wales [NSW] Health (2004). Aboriginal terminology. Retrieved December 19, 2011, from http://www.health.nsw.gov.au/pubs/2004/aboriginal_terms.html

O’Donohue, L. (1999). Towards a culture of improving Indigenous health in Australia. Australian Journal of Rural Health, 7, 64-69.

Orford, J., Natera, G., Copello, A., Atkinson, C., Mora, J., Velleman, R., et al. (2005). Coping with alcohol and drug problems: The experiences of family members in three contrasting cultures. East Sussex, UK: Routledge.

Ray, R. A., \& Street, A. F. (2005). Ecomapping: An innovative research tool for nurses. Journal of Advanced Nursing, 50, 545-552.

Read, P. (1981). The Stolen Generations: (bringing them home). The removal of Aboriginal children in New South Wales 1883 to 1969. Department of Aboriginal Affairs (New South Wales Government). Retrieved December 19, 2011, from http://www.daa.nsw.gov.au/publications/ StolenGenerations.pdf.

Rempel, G. R., Neufeld, A., \& Eastlick Kushner, K. (2007). Interactive use of genograms and ecomaps in family caregiving research. Journal of Family Nursing, 13, 403.

Rigazio-DiGilio, S. A., Ivey, A. E., Kunkler-Peck, K. P., \& Grady, L. T. (2005). Community genograms: Using individual, family, and cultural narratives with clients. New York: Teachers College Press.

Roche, A. M., Pidd, K. J., \& Duraisingam, V. (2009). The capacity of mainstream alcohol and drug treatment services to respond to the needs of Indigenous Australians. Medical Journal of Australia, 190, 582. 


\section{J. Stewart \& J. Allan}

Secretariat of National Aboriginal and Islander Child Care [SNAICC]. (2008). Service development cultural respect and service access policy. Retrieved December 19, 2011, from http://www. snaicc.asn.au/_uploads/rsfil/02497.pdf

Shellenberger, S., Dent, M.M., Davis-Smith, M., Seale, J. P., Wientraut, R., \& Wright, T. (2007). Cultural genogram: A tool for teaching and practice. Families, Systems, Health, 25, 367-381.

Skowron, E. A., Holmes, S. E., \& Sabatelli, R. (2003). Deconstructing differentiation: Self-regulation, interdependent relating, and well-being in adulthood. Contemporary Family Therapy: An International Journal, 25, 111-129.

Victorian Aboriginal Child Care Agency. (2008). Aboriginal cultural competence framework. Melbourne, Vic: Victorian Government Department of Human Services, Melbourne.

Yanicki, S. (2005). Social support and family assets. Canadian Journal of Public Health, 96, 46-49.

Yznaga, S. D. (2008). Using the genogram to facilitate the intercultural competence of Mexican immigrants. Family Journal: Counseling and Therapy for Couples and Families, 16, 159-165.

Zubrick, S. R., Silburn, S. R., Lawrence, D. M., Mitrou, F. G., Dalby, R. B., Blair, E. M., et al. (2005). The Western Australian Aboriginal child health survey: The social and emotional wellbeing of Aboriginal children and young people. Perth, WA: Curtin University of Technology and Telethon Institute for Child Health Research. 